\title{
Açık hava antik alanı (OASIS) yapı taşlarında gözlenen bozunmanın nümerik hesaplama ile belirlenmesi
}

\author{
KIvanç ZORLU ${ }^{*}$, Mehmet BAYIRLI ${ }^{2}$ \\ ${ }^{1}$ Mersin Üniversitesi, Mühendislik Fakültesi, Jeoloji Mühendisliği Bölümü Mersin \\ ${ }^{1}$ Balıkesir Üniversitesi, Fen Edebiyat Fakültesi, Fizik Bölümü, Çağış Kampüsü, Balıkesir \\ Gelis Tarihi (Recived Date): 21.09.2017 \\ Kabul Tarihi (Accepted Date): 20.10 .2017
}

Özet

Karbonatl kayalarda bozunma derecesinin belirlenmesi oldukça zordur. Bu tür kayaların özellikle çözünmeye duyarlı olmaları nedeniyle, bozunma artıkları ortamdan tamamen uzaklaşarak ve kaya içerisinde boşluklar oluştururlar. Ayrıca, koruma altındaki tarihi yerlerdeki yapı taşlarında meydana gelen bozunmanın belirlenmesi de, örneklemede yaşanan sinırlamalar nedeniyle oldukça güçtür. Akdeniz kıyılarında inşa edilmiş tarihi yapılar, büyük bloklar elde edilebilen ve yapı taşları için uygun niteliklerde olan kireçtaşları ile inşa edilmiştir. Olba antik kentinin yapı taşlarında çözünme ile meydana gelen makro ve mikro ölçekteki bozunmanın izlerine rastlamak mümkündür. Örnek almadaki kısıtlamalar nedeniyle Olba antik kentindeki yapı taşlarının mikro ölçekteki bozunma derecelerini belirlemek için hasar vermeyen bir yöntem kullanılmıştır. Çalışmada, yapı taşlarının mikro ölçekteki yüzey morfolojisi fraktal boyut yaklaşımı kullanılarak belirlenmiştir. Bu amaçla, farklı bozunma derecelerine sahip yapı taşlarından alınan örnekler Taramalı Elektron Mikroskobunda (SEM) analiz edilmiş ve her bir mineralin fraktal boyutu hesaplanmıştır. Elde edilen sonuçlara göre, yapı taşlarındaki bozunma arttıkça, fraktal boyutta da bir artış gözlenmektedir. $\mathrm{Bu}$ sonuçlar, daha önce makro ölçekte yapılmış çalışmalarda belirlenen bozunma dereceleri ile uyumluluk göstermektedir.

Anahtar Kelimeler: Olba, bozunma, SEM, fraktal boyut.

\section{Assessment of weathering degree of building stones of open air ancient sites (OASIS) by numeric computation}

\begin{abstract}
Assessment of the weathering degree of carbonate rocks is very difficult because carbonates are particularly susceptible to solution which can lead to almost complete removal of the weathering products in solution and than rocks contains significant voids. Studying weathering states of building stones in historical places under conservation are also difficult because of sampling limitations. The ancient buildings have been constructed with limestone in Mediterranean costs, because of ability to have large blocks and suitability as building stones. It is possible to observe traces of solution weathering in the building stones of the buildings of the Olba ancient city in macro and micro scale. Due to sampling restriction, some non-destructive methods are applied to determine weathering state of building stones in micro scale in Olba ancient city. In this purpose, this study investigates surface morphology of the building stones in micro scale using self-affine fractal behaviours. For this reason, Scanning Electron Microscope (SEM) analyses were carried out on small samples for the calculation of fractal dimension of each mineral obtained from building stones has different
\end{abstract}

\footnotetext{
*Kıvanç ZORLU, kivancgeo@ mersin.edu.tr, http://orcid.org/0000-0002-2086-7379

Mehmet BAYIRLI, mbayirli@balikesir.edu.tr, http://orcid.org/0000-0002-7775-0251
} 
weathering states. According to analysis, the increment in the weathering degree is lead to increasing the fractal dimension. This result is consistent with previous study carried out in macro scale.

Keywords: Olba, weathering, SEM, fractal dimension.

\section{Giriş}

Açık hava antik kentleri kontrollü girişin yapıldığı ve koruma altına alınmış alanlar olmakla birlikte, bu uygulama insan etkisiyle tahribatı önlemede sınırlı bir etki yapmaktadır ancak, jeolojik ve meteorolojik etkilere karşı koruma sağlamamaktadır. Zaman içerisinde, yıllık sıcaklık değişimleri, radyasyon, nem, yağış gibi meteorolojik faktörlere maruz kalan açı-hava antik kent alanlarının yapı taşları, mineraloji, doku ve mühendislik özellikleri gibi jeolojik faktörlerin değişimleri ile büyük ölçüde doğal tahribata uğramaktadır. Bu yapılarda yapılacak çalışmaların, tarihi yapılara zarar vermeden yürütülmesi zorunludur ve bu nedenle bozunma çalışmalarının laboratuvar yöntemlerin dışında nümerik yöntemlerle yapılması gerekmektedir.

Akdeniz Bölgesi, insanlığın başlangıcından bu yana uygarlığın beşiği olarak kabul edilen en önemli bölgelerden biridir. Mersin ili de jeolojik konumu ile tarihi zenginlikleri bakımından Akdeniz Bölgesi'nin en dikkat çekici bölgelerinden biridir. Mersin ili ve ilçelerini kapsayan geniş bir alan içerisinde, Helenistik dönemden Bizans dönemine kadar uzanan tarihi süreçte kurulmuş pek çok antik kent mevcuttur. $\mathrm{Bu}$ kentlerin en dikkat çekici özellikleri, deniz kıyısından başlayarak $1100 \mathrm{~m}$ yüksekliğe kadar olan bölgelerde kurulmuş olmaları ve kentlerin inşasındaki yapı taşlarında, bölgenin en yaygın birimi olan kireçtașlarının kullanılmıș olmasıdır [1]. Karbonatlı kayaçlarda bozunma durumunun belirlenmesi oldukça güçtür. Çünkü karbonatlar çözünme yoluyla bozunmaya duyarlıdır ve bozunma ürünleri neredeyse tamamen ortamdan uzaklaşır. Ayrıca kütle ölçeğinde önemli boşluklar içerir. Bu nedenle yapılacak bozunma çalışmaları, mineralojik ve petrografik analizler ile sinırlı kalmamaktadır.

Bozunma, kimyasal bozunma ve fiziksel parçalanma ile atmosfere açık kesimlerde bulunan kaya ve toprak malzemelerinin mineralojik olarak değişikliğe uğraması ve parçalanması sürecidir [2]. Zorlu [3], açık hava antik alanlarındaki karbonatlı yapı taşlarının bozunma derecelerini tanımlamaya yönelik, arazi gözlemlerini temel alan, gözlemsel bir sınıflama sistemi geliştirmiş̧tir. Bu sınıflamada yapı taşları; az bozunmuş (SW), orta derecede bozunmuș (MW) ve bozunmuș (W) olmak üzere üç grupta toplanmıştır. Bu görsel sınıflandırmaya göre toplam 114 yapı taşı sınıflandırılmıştır.
Blokların 25 tanesi az bozunmuș olarak siniflandırılırken 37 tanesi orta derecede bozunmuş olarak sınıflandırılmıştır. Yapı taşlarının görsel sınıflamasına ek olarak, her bloğun fraktal boyutları (Df), bunların bozunma derecelerine göre hesaplanmıştır. $\mathrm{Bu}$ çalışmada, minerallerin bozunma durumları Zorlu [3] tarafindan ortaya konan bozunma siniflaması dikkate alınarak sınıflandırılmıştır.

Fraktal kelimesi literatüre ilk kez Mandelbrot [4] ile girmiş ve kendine oldukça geniş kullanım alanları bulmuştur. Doğada hiçbir şeyin düzenli bir şekli olmamasından yola çıkılarak ortaya atılmış olan bu kavramda, düzensizliklerin ve parçalılığın matematiksel olarak farklı ölçeklerdeki ifadesi kullanılmaktadır. $\mathrm{Bu}$ çalışma kapsamında, bozunmaya bağlı olarak yapıtaşlarında meydana gelen geometrik değişimlere, fraktal geometri ve fraktal boyut kavramları uygulanarak belirlenmişstir.

\section{Materyal ve yöntem}

Çalışmada, Olba antik kentinin farklı bozunma derecelerine sahip yapı taşlarından elde edilen küçük el örnekleri kullanılmıştır. Çalışılan örneklerin bozunma dereceleri, Zorlu [3] tarafından önerilen makro ölçekteki (Tablo 1) bozunma sinıflaması dikkate alınarak sınıflandırılmıştır.

Tablo 1. Zorlu [3] tarafından önerilen ve çalışmada kullanılan gözleme dayalı bozunma siniflamasi

\begin{tabular}{|c|c|}
\hline Bozunma Sınıfi & Tanımlama \\
\hline Az Bozunmuş (SW) & $\begin{array}{l}\text { Bloklar orijinal şeklini koruyor. } \\
\text { Bazı insan yapımı izler } \\
\text { gözlenmekte. Sadece küçük erime } \\
\text { boşlukları ve renk değişimleri } \\
\text { mevcut. Genellikle bu tür bloklar } \\
\text { likenle kaplı. }\end{array}$ \\
\hline $\begin{array}{l}\text { Orta Derecede } \\
\text { Bozunmuş (MW) }\end{array}$ & $\begin{array}{l}\text { Genellikle kenarlar ve köşeler } \\
\text { erime ile yuvarlaklaşmış. Yüzeyler } \\
\text { kısmen likenle kaplı. Erime } \\
\text { boşluklarının boyutu en fazla } 1 \\
\text { cm. }\end{array}$ \\
\hline Bozunmuş (W) & $\begin{array}{l}\text { Bloklar orijinal şekli tamamen } \\
\text { kaybetmiş. Yüzeyler tamamen } \\
\text { renk değiştirmiş ve bozunma } \\
\text { kabuğu gözlenmekte. }\end{array}$ \\
\hline
\end{tabular}

$\mathrm{Bu}$ çalışmada, OK- olarak adlandırılan örneklerin bozunma durumları fraktal analiz yöntemlerini kullanılarak belirlenmiştir. İlk olarak, sekiz küçük 
örneğin mikro ölçekteki fraktal boyutlarının belirlenebilmesi için petrografik analizle ve SEM analizleri yapılmıştır. Tipik SEM analiz görüntüleri Şekil 1'de sunulmuş ve petrografik analiz sonuçları Tablo 2'de verilmiştir.
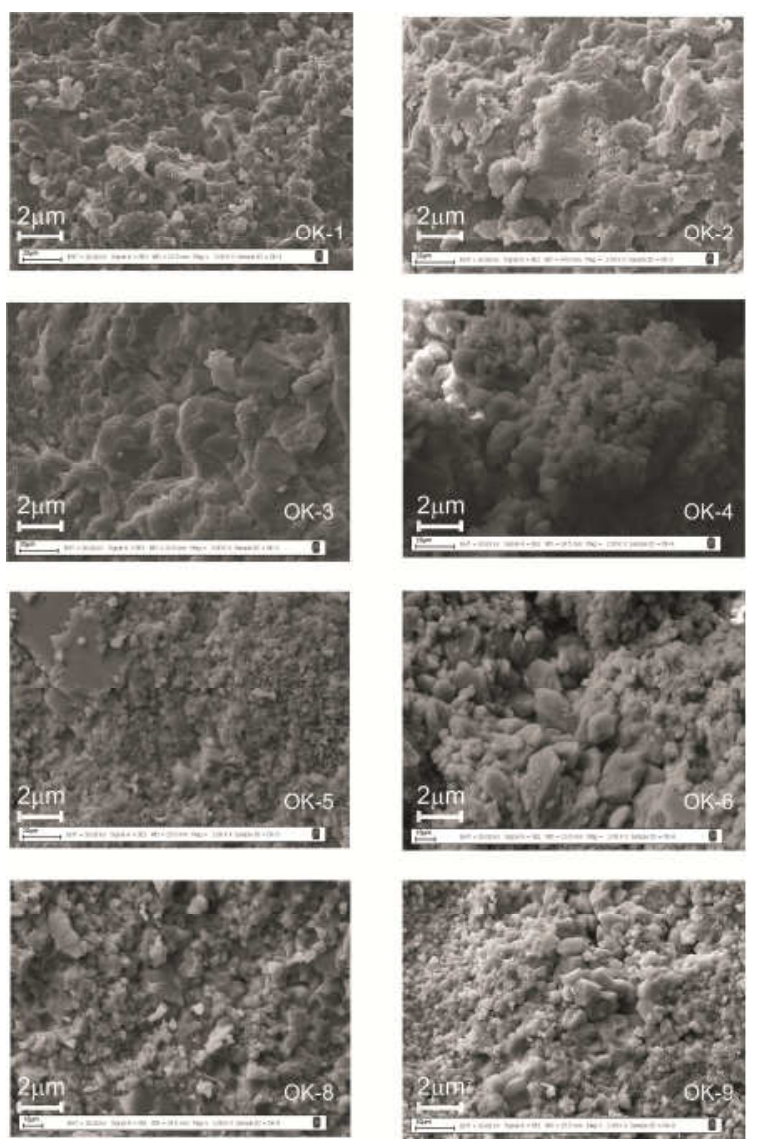

Şekil 1. SEM analizlerinin sonuçları
Analizlerin ikinci aşamasında, örneklerin SEM görüntüleri, fraktal boyut (Df) hesaplamaları için bilgisayar ortamına aktarılmıştır. Fraktal boyut hesaplamalarında imageJ ve Gwyddion yazılımları kullanılmıştır. Görüntüler, Gaussian blur kullanılarak filtrelenip, BMP resim formatına dönüştürülmüştür. $\mathrm{Bu}$ şekilde $\mathrm{SEM}$ görüntülerindeki minerallerin yüksek kontrastı elde edilerek, hem mineral yüzeyleri hem de mineral kenarları net bir şekilde tanımlanabilmiştir (Şekil 2).

Fraktal boyutları hesaplamak için 5 farklı yöntem kullanılmıştır. Fraktal boyutlar, asıl yöntem olarak kullanılan kutu sayma (box counting) yönteminin yanı sıra, küp sayma yöntemi (cube counting), varyans yöntemi (variance), üçgenleştirme yöntemi (triangulation), ve güç spektrumu yöntemi (power spectrum) ile hesaplanmıştır. Kutu-sayma yönteminde en küçük kareler yöntemi, küp sayma, üçgenleştirme, varyans ve güç spektrumu yöntemlerinde ise doğrusal interploasyon (linear interpretation) yöntemi kullanılmıştır.

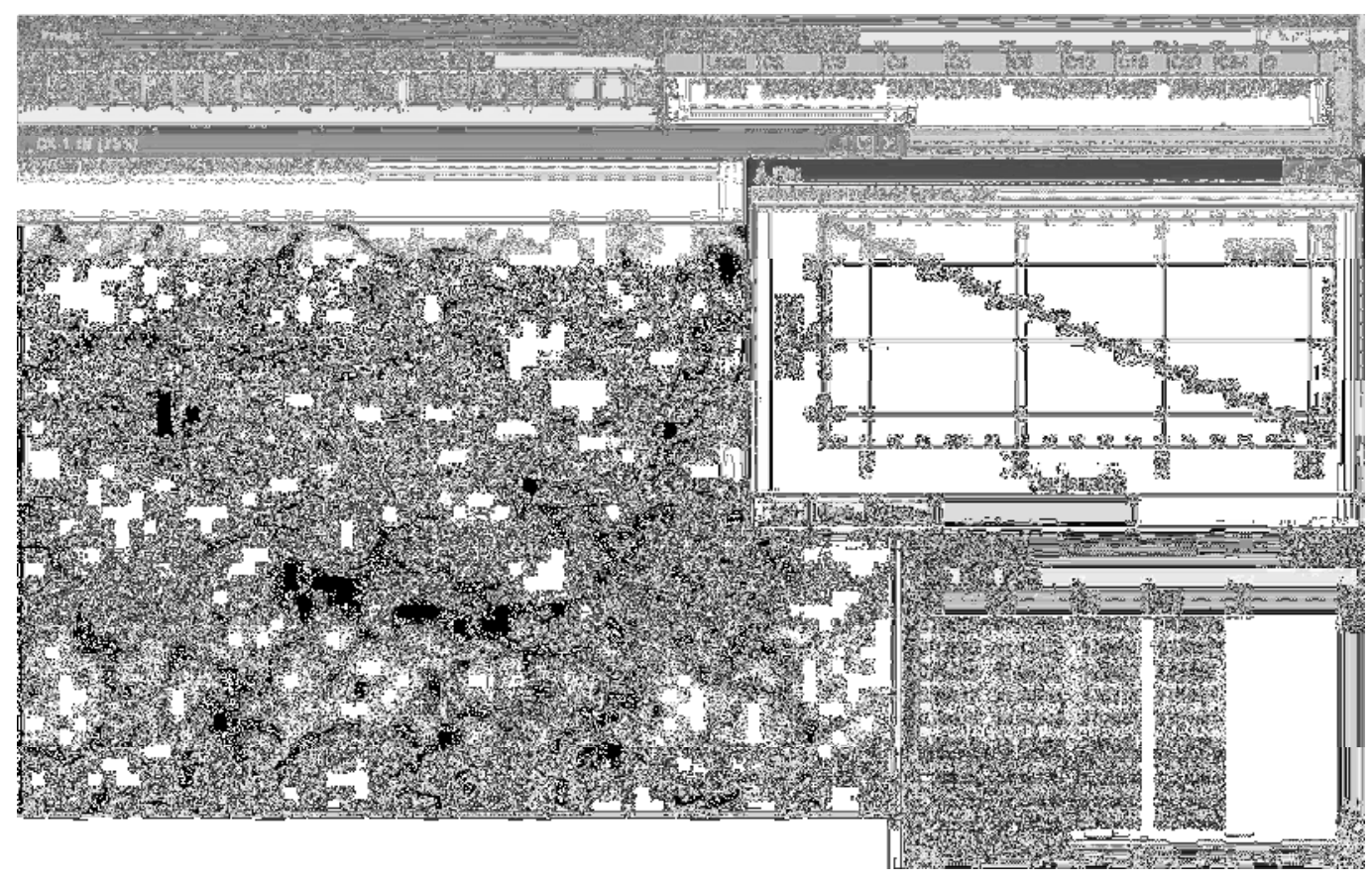

Şekil 2. imageJ programı kullanılarak hesaplanan fraktal boyutların analiz aşaması. 
Tablo 2. Bozunma sınıflarının petrografik analiz sonuçları

\begin{tabular}{|c|c|c|}
\hline Bozunma sınıfi & Petrografik tanımlama & Örnek \\
\hline $\begin{array}{l}\text { Az bozunmuş } \\
(\mathrm{SW})\end{array}$ & $\begin{array}{l}\text { İstiftaşı, Biyomikrit. Mikrit içinde fosil ve karbonat tanelerinden oluşuyor. Fosillerin bazıları } \\
\text { kırıklar, parçalar halinde, bazıları da tam olarak izleniyor. Ayrıca küçük çözünme boşlukları } \\
\text { da gözleniyor. } \\
\text { İstiftaşı, Biyomikrit. Mikrit içinde fosil ve karbonat tanelerinden oluşuyor. Fosillerin bazıları } \\
\text { kırıklar, parçalar halinde, bazıları da tam olarak izleniyor }\end{array}$ & OK-8 \\
\hline $\begin{array}{l}\text { Orta derecede } \\
\text { bozunmuş } \\
(\mathrm{MW})\end{array}$ & $\begin{array}{l}\text { İstiftaşı, Biyomikrit. Karbonat çamurunun içinde fosil kırıntıları ile karbonat taneleri içeriyor. } \\
\text { Buna ek olarak yer yer çözünme boşlukları da mevcut. } \\
\text { İstiftaşı, Biyomikrit. Bol miktarda fosil mikritik bir çamur içinde bulunuyor. Fosillerin bazıları } \\
\text { tamken, bazıları kırıklar halinde. Karbonat taneleri de mevcut ancak oransal olarak az } \\
\text { bulunmaktadırlar. } \\
\text { İstiftaşı, Biyosparit. Sparit ve bol miktarda fosilden oluşuyor. İri bir çözünme boşluğu ve onun } \\
\text { etrafında gelişmiş karbonat sarılımları izleniyor. Ayrıca küçük çözünme boşlukları da } \\
\text { bulunuyor. } \\
\text { İstiftaşı, Biyomikrit. Bol fosil içeriyor. Örneğin mikritik olmasına rağmen yer yer sparitler de } \\
\text { bulunuyor. Küçük çözünme boşlukları izleniyor. }\end{array}$ & OK-5 \\
\hline $\begin{array}{c}\text { Bozunmuş } \\
(\mathrm{W})\end{array}$ & $\begin{array}{l}\text { Mikritik kireçtaşı/çamurtaşı. Çok az miktarda fosil içeriyor. Örneğin dış yüzeyine doğru } \\
\text { yaygın bir alterasyon mevcut. } \\
\text { İstiftaşı, Biyosparit. Tamamen sparit içinde bol miktarda fosilden oluşuyor. Az ve küçük } \\
\text { olmak kaydıyda çözünme boşlukları da içeriyor. }\end{array}$ & OK-4 \\
\hline
\end{tabular}

$\mathrm{Bu}$ çalışmada fraktal boyutların hesaplanmasında kullanılan temel yöntem kutu-sayma (boxcounting) yöntemi kullanılmıştır. Kutu-sayma yöntemidir. $\mathrm{Bu}$ yöntem için geliştirilen algoritma, görüntüyü piksellerini kutulara bölüp her bir kutunun dolu veya boş olmasına göre (pikselde siyah görüntü varsa yani o kutu dolu ise 1, kutu boş ise 0 alarak) sayma işlemidir. Piksel genişliğindeki kutular, $\varepsilon$ ve taranmış resimdeki toplam genişlik $N(\varepsilon)$ olmak üzere her adım için $(\varepsilon=1, \quad 2,4,16, \ldots \ldots .$. piksel $)$ 2'nin kuvvetleri şeklinde değişmektedir ve $\varepsilon$ kutu boyutu artarken $N(\varepsilon)$ hesaplanmaktadır. Çizilen $\log N(\varepsilon)-\log \varepsilon$ grafiği doğrusal bir grafik olup, doğrunun eğiminden fraktal boyut (Df) hesaplanmakta ve aşağıdaki eşitlik ile tanımlanmaktadır.

$$
D f=\lim _{\varepsilon \rightarrow 0} \frac{\log N(\varepsilon)}{-\log (1 / \varepsilon)}
$$

Küp sayma yöntemi

Küp sayma yöntemindeki algoritma basamaklar halinde gelişmektedir Öncelikle örgü sabiti $l$ olan bir kübik örgüde $\mathrm{z}$-genişletilmiş yüzey üzerine bindirilmektedir. Başlangıçta $l$, X / 2 (X'in yüzey kenarının uzunluğu) olarak ayarlandığı için, $2 \times 2$ $\times 2=8$ küp üç boyutlu mini bir örgü (kafes) oluşturmaktadır. $\mathrm{N}(l)$, resmin en az bir pikselini içeren tüm küplerin sayısıdır. Daha sonra, örgüt sabiti $l$, kademeli olarak 2 faktörü ile azaltılarak işlem iki bitişik piksel arasındaki mesafeye eşit olana kadar tekrarlanmaktadır. Bu şekilde $(\mathrm{N}(l))$ ile $\log (1 / l)$ nin arasındaki eğimin değeri fraktal boyut (Df) olarak belirlenmektedir [6-8].

\section{Üçgenleştirme yöntemi}

$\mathrm{Bu}$ yöntem küp sayma yöntemine çok benzer bir yöntemdir. Bir birim boyut $\varepsilon$ hücresi üzerine yerleştirilmektedir. $\mathrm{Bu}$, üçgenlerin köşelerinin konumunu tanımlamaktadır. Örneğin, $\varepsilon=\mathrm{X} / 4$ olduğu zaman, yüzey, xy düzlemine göre çeşitli açılarda eğimli 32 bölgenin üçgeniyle kaplanmaktadır. Tüm üçgenlerin alanları hesaplanarak l'ye karşılık gelen yüzey alanı $S(\varepsilon)$ 'nin yaklaşık elde edilmesi amacıyla toplanmaktadır. Hücre boyutu, ard arda gelen faktör 2 ile azaltılarak süreç, $\varepsilon$, bitişik iki piksel noktası arasındaki mesafeye denk gelene kadar devam etmektedir. $(S(\varepsilon))$ ile $\log (1 / \varepsilon)$ arasındaki eğimin değeri Df 'ye karşılık gelmektedir [6].

Varyans yöntemi

$\mathrm{Bu}$ yöntemde, yüzey eşit boyutlu kare kutulara bölünmekte ve varyans belirli bir kutu boyutu için hesaplanmaktadir. Fraktal boyut, log-log dağılımında, veri noktalarına uyan, en küçük kare regresyon çizgisinin $\beta$ eğrisinden Df $=3-\beta / 2$ olarak hesaplanmaktadır [5-7].

Güç spektrumu yöntemi

$\mathrm{Bu}$ yöntemde, görüntüyü oluşturan her satır yüksekliğinin profili Fourier ile dönüştürülmekte ve daha sonra güç spektrumlarının ortalaması alınmaktadır. Fraktal boyut, spektrumların log-log grafiğindeki veri noktalarına uyan, en küçük kareler regresyon çizgisinin $\beta$ eğrisinden Df $=7 / 2$ $\beta / 2$ olarak hesaplanmaktadır [5-6-7-9].

Fraktal boyut hesaplamalarında kullanılan farklı yöntemlerin çıkış noktalarının aynı mantıksal yaklaşımda kesişiyor olmalarına rağmen sonuçların değişkenliği olası bir durumdur. Bunun, farklı fraktal analiz yaklaşımlarının sistematik hatasından kaynaklandığı unutulmamalıdır.

\section{Bulgular}

Kutu sayma yöntemini kullanarak, OK-1, OK-2, OK-3, OK-3, OK-4, OK-5, OK-6, OK-8 ve OK-9 için hesaplanan fraktal boyutlara (Df) ait grafikler, 
Şekil 3'de verilmiştir. Fraktal boyut hesaplamalarında yanal uzunluk L $=1024 \mu \mathrm{m}$ olarak alınmıştır. Elde edilen sonuçlar, bozunma derecesinin artması ile minerallerin ortalama fraktal boyutun azaldığını göstermektedir. Bozunmuş, orta derecede bozunmuş ve az bozunmuş minerallerin ortalama fraktal boyutları sırasıyla; $1.76,1.78$ ve 1.8 'dir (Tablo 3). Zorlu [3] tarafından yayınlanan önceki çalışmada, Bozunmuş, orta derecede bozunmuş ve az bozunmuş minerallerin ortalama fraktal boyutları sırasılya; $1.80,1.83$ ve 1.88 'dir. $\mathrm{Bu}$ sonuçlar, makro ölçekte açık hava antik kentin yapı taşlarında elde edilen ortalama fraktal boyut değerleri ile benzerlik göstermektedir.
Tablo 3. Kutu sayma yöntemi kullanılarak hesaplanan bozunma derecelerine göre fraktal boyut değerleri

\begin{tabular}{ccccc}
\hline $\begin{array}{c}\text { Bozunma } \\
\text { dercesi }\end{array}$ & Örnek & $\begin{array}{c}\text { Maksimum } \\
\text { Fraktal } \\
\text { boyut }\end{array}$ & $\begin{array}{c}\text { Minimum } \\
\text { fraktal } \\
\text { boyut }\end{array}$ & $\begin{array}{c}\text { Ortalama } \\
\text { fractal } \\
\text { dimension }\end{array}$ \\
\hline SW & $\begin{array}{c}\text { OK-8 } \\
\text { OK-9 }\end{array}$ & 1.80 & 1.78 & 1.79 \\
& OK-1 & & & \\
MW & OK-3 & 1.68 & 1.74 & 1.78 \\
& OK-5 & & & \\
OK-6 & OK-2 & 1.75 & 1.78 & 1.76 \\
\hline
\end{tabular}
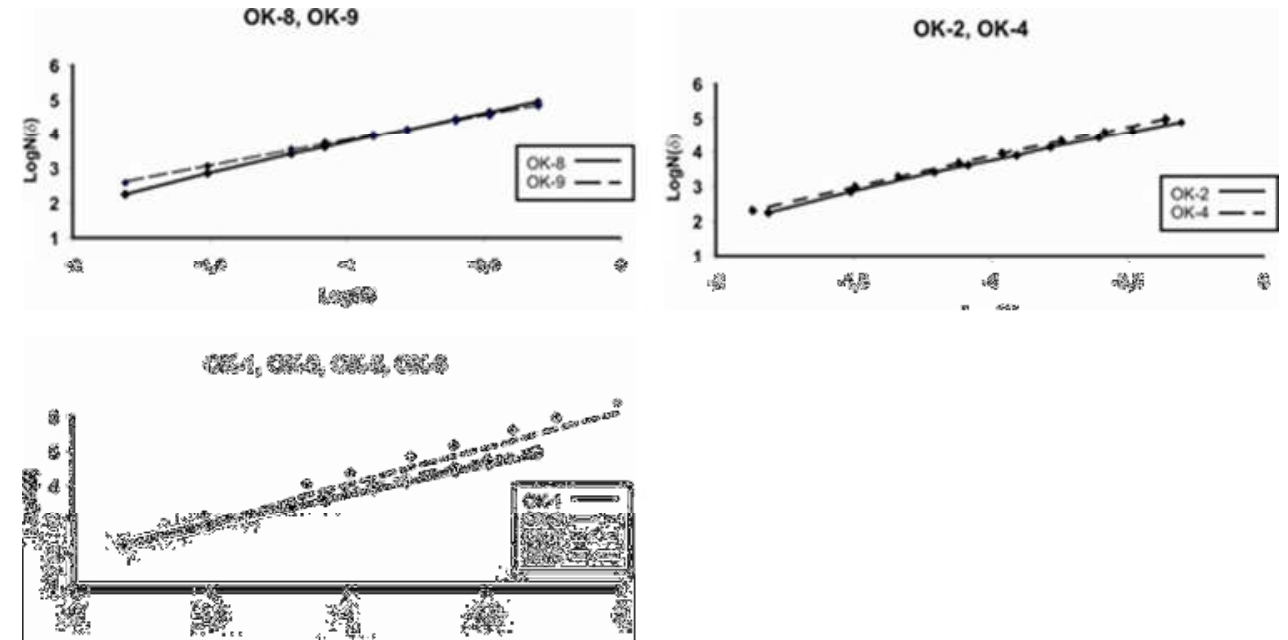

Şekil 3. Farklı bozunma derecelerine sahip 8 küçük örneğin fraktal boyutları.
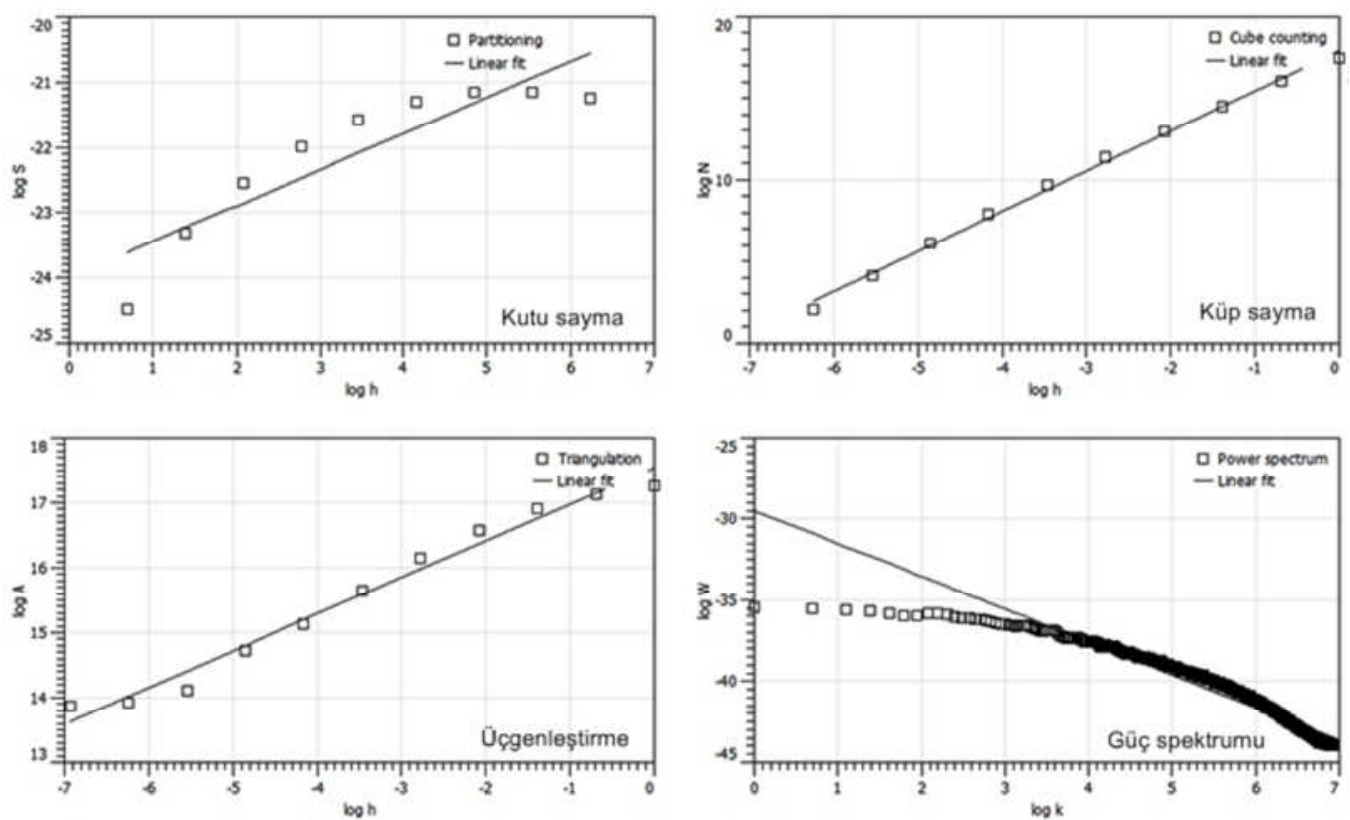

Şekil 4. Fraktal boyut hesaplamalarında kullanılan küp sayma, üçgenleştirme, varyans ve güç spektrumu yöntemlerinden elde edilen tipik fraktal boyut grafiklerine örnekler. 
Tablo 4. Doğrusal ve dairesel enterpolasyon kullanılarak, varyans, küp sayma, üçgenleştirme ve güç spektrumu yöntemlerinden elde edilen fraktal boyutlar

\begin{tabular}{cccccccccc}
\hline Fraktal boyutlar & Örnek & OK-1 & OK-2 & OK-3 & OK-4 & OK-5 & OK-6 & OK-8 & OK-9 \\
\hline & Varyans & & 2.76 & 2.73 & 2.72 & 2.57 & 2.77 & 2.66 & 2.70 \\
Doğrusal & Küp sayma & 2.48 & 2.54 & 2.48 & 2.46 & 2.57 & 2.51 & 2.53 & 2.54 \\
enterpolasyon* & Üçgenleştirme & 2.58 & 2.61 & 2.58 & 2.48 & 2.64 & 2.55 & 2.60 & 2.62 \\
& Güç spektrumu & 2.58 & 2.61 & 2.58 & 2.48 & 2.64 & 2.55 & 2.60 & 2.62 \\
\hline \multirow{2}{*}{ Dairesel } & Varyans & 2.72 & 2.69 & 2.68 & 2.52 & 2.72 & 2.62 & 2.65 & 2.66 \\
enterpolasyon* & Küp sayma & 2.46 & 2.5 & 2.45 & 2.41 & 2.53 & 2.46 & 2.49 & 2.50 \\
& Üçgenleştirme & 2.57 & 2.58 & 2.55 & 2.43 & 2.60 & 2.51 & 2.57 & 2.59 \\
& Güç spektrumu & 2.49 & 2.61 & 2.56 & 2.68 & 2.75 & 2.65 & 2.62 & 2.55 \\
\hline
\end{tabular}

Yapı taşlarında ait mineralin fraktal boyutları, küp sayma yöntemi, üçgenleştirme yöntemi, varyans ve güç spektrumu yöntemi gibi diğer popüler yöntemler için de hesaplanmıştır (Şekil 4). Bu yöntemler kullanılarak elde edilen fraktal boyutlarının sonuçları Tablo 4'te verilmiştir. Hem doğrusal hem de dairesel enterpolasyon için hesaplamalarında yanal uzunluk $1000 \mu \mathrm{mx} 68 \mu \mathrm{m}$ alınmıştır. Şekil 5'den de görülebileceği gibi, dört yöntem arasındaki korelasyonlar, kutu sayım yönteminde olduğu gibi benzer karakteristik fraktal boyut değeri sergilemektedir. $\mathrm{Bu}$, fraktal geometri yaklaşımlarından herhangi bir yöntemin bu tür araştırmalarda kullanabileceğini göstermektedir.
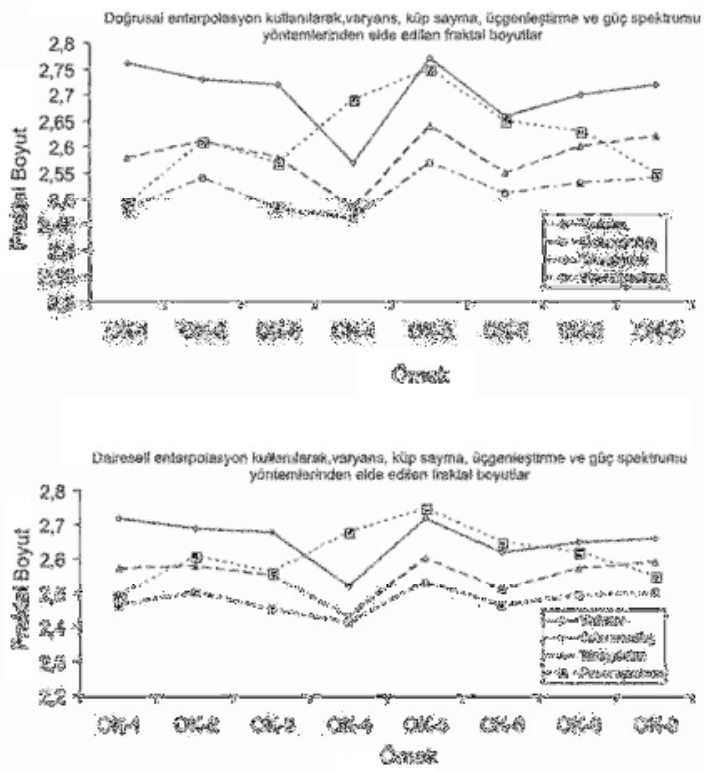

Şekil 5. Varyans, küp sayma, üçgenleştirme ve güç spektrumu yöntemlerinden elde edilen fraktal boyutların karşılaştırması

\section{Kaynakça}

[1] Erten, E., Archaeological Surveys at Olba (Uguralani), Silifke-Mersin. Mersin University, Department of Archaeology, internal report, 5p (unpublished) (2003).

\section{Tartışma ve sonuç}

Açık hava antik alanlarında yapılan çalışmalarında, bu alanların koruma altında olması nedeniyle, örnekleme yapılamamakta ve yapı taşlarının bozunma derecelerinin belirlenmesinde laboratuvar deneylerinin yerine zarar vermeyen yöntemlere gereksinim duyulmaktadır. Bu çalışmada Olba (Mersin) açık hava antik kentinin yerleşim alanında, kireçtaşından oluşan yapı taşlarındaki çözünme türü bozunmanın mineral boyutundaki etkisi, fraktal geometri ile belirlenmiştir. $\mathrm{Bu}$ yöntem koruma altında olan tarihi alanlarda, herhangi bir anıt yapıya zarar vermeden, yapı taşlarının bozunma derecelerinin belirlenmesinde kullanılabilecek uygun bir yaklaşım olarak ortaya konmuştur. Bu amaçla, daha önce makro boyutta yap1 taşı bloklarında önerilmiş olan gözlemsel bir sınıflama dikkate alınarak, mineral boyutunda yapı taşlarının bozunma dereceleri fraktal boyutla belirlenmeye çalışılmıştır. Fraktal boyut hesaplamalarında beş ayrı yaklaşım kullanılmıştır. Bu yöntemlerden kutu sayma yöntemi başta olmak üzere, uygulanan diğer dört yöntemde (varyans, küp sayma, üçgenleştirme ve güç spektrumu yöntemleri) de makro boyutta hesaplanan fraktal boyut değerlerine benzer sonuçlar alınmıştır. Bu çalışmanın sonuçları, fraktal geometri uygulaması gibi bazı nümerik yaklaşımların özellikle koruma altındaki tarihi alanlarda, yapı taşlarının bozunma derecelerinin tanımlanmasında ve kantitatif olarak değerlendirilmesinde kullanılabilir olduğunu göstermektedir.

[2] Anonymous, The description and classification of weathered rocks for engineering purposes, Engineering Group Working Party Report, Quarterly Journal of Engineering Geology and Hydrogeology, 28, 207-242. (1995) doi:10.1144/GSL.QJEGH.1995.028.P3.02. 
[3] Zorlu, K., Description of the weathering states of building stones by fractal geometry and fuzzy inference system in the Olba ancient city (Southern Turkey), Engineering Geology, 101, 3-4, 124-133, (2008).

[4] Mandelbrot, B.B., How long is the coast of Britain? Statistical self-similarity and fractal dimension, Science, 155, 636-638. (1967).

[5] Van Put, A., Vertes, A., Wegrzynek, D., Treiger, B. and Van Grieken, R., Quantitative characterization of individual particle surfaces by fractal analysis of scanning electron microscope images, Fresenius' Journal of Analytical Chemistry, 350, 440-447, (1994).

[6] Douketis, C., Wang, Z., Haslett, T.L. and Moskovits, M., Fractal character of cold- deposited silver films determined by lowtemperature scanning tunneling microscopy, Physical Review B, 51, 16, 15-51, (1995).

[7] Mannelquist, A., Almquist, N. and Fredriksson, S., Influence of tip geometry on fractal analysis of atomic force microscopy images, Applied Physics A, 66, 891-895, (1998).

[8] Zahn, W. and Zösch, A., The dependence of fractal dimension on measuring conditions of scanning probe microscopy, Fresenius' Journal of Analytical Chemistry, 365, 168-172. (1999).

[9] Zahn, W. and Zösch, A., Characterization of thin film surfaces by fractal geometry. Fresenius Journal of Analen Chemistry, 358, 119-121, (1997). 